Artículo Original

\title{
Una segunda especie del género Eanus (Eanus) LeConte (Coleoptera: Elateridae: Athoinae) para Chile
}

A second species of the genus Eanus (Eanus) LeConte (Coleoptera: Elateridae: Athoinae) for Chile

\author{
Cristian Pineda ${ }^{1}$
}

${ }^{1}$ Av. El Litre N¹310, Valparaíso, Chile. 隐 cristian.pineda.r@gmail.com

ZooBank: urn:lsid:zoobank.org:pub: 17C6E171-E65C-455F-9A2B-9FA6F4414BBC

https: / / doi.org/ 10.35249/ rche.46.4.20.03

Resumen. Se describe e ilustra una segunda especie de Eanus LeConte, 1861, procedente de la zona cordillerana de la Región de Nuble, Chile.

Palabras clave: Corymbites, Ctenicera, Ctenicerini, subgénero, taxonomía.

Abstract. A second species of Eanus LeConte, 1861, from the mountain range area of Nuble Region, Chile, is described and illustrated.

Key words: Corymbites, Ctenicera, Ctenicerini, subgenus, taxonomy.

\section{Introducción}

El género Eanus LeConte, 1861 está compuesto por dos subgéneros: Pareanus Gurjeva, 1989 y Eanus LeConte, 1861. El subgénero Pareanus contiene dos subespecies propias de Japón: E. (P.) costalis costalis Paykull, 1800 y E. (P.) costalis shibatai Kishii, 1968. Eanus (Eanus) contiene hasta el momento una única especie de Chile y Argentina: Eanus (E.) philippii (Fleutiaux, 1910), descrita originalmente como Corymbites philippii en base a un número no especificado de especímenes provenientes de Osorno, Chile (Fleutiaux 1910; Tarnawski 2001; Arias-Bohart y Elgueta 2012). Lane (1948) establece a Corymbites Latreille, 1834 como sinónimo de Ctenicera Latreille, 1829, originando la nueva combinación Ctenicera philippii (Fleutiaux). Posteriormente, Tarnawski (2001) transfiere esta especie al género Eanus (Eanus), quedando finalmente como Eanus (E.) philippii (Fleutiaux).

El propósito de esta contribución es describir una segunda especie de Eanus proveniente de la zona cordillerana de la Región de Ñuble, Chile.

\section{Materiales y Métodos}

Para la descripción morfológica se sigue en parte la terminología utilizada por Calder (1996). Las fotografías de los hábitos dorsales fueron tomadas con el espécimen fijado en una plataforma Nikon PB-6M por medio de un lente Micro-NIKKOR 55mm f/3.5 acoplado a un fuelle Nikon PB-6 y éste a una cámara Nikon D7000. Las fotografías de partes aumentadas fueron tomadas de la misma manera, pero con un lente de microscopio

Recibido 10 Septiembre 2020 / Aceptado 28 Septiembre 2020 / Publicado online 30 Octubre 2020 Editor Responsable: José Mondaca E. 
Nikon M Plan 10×0.25 210/0. En el caso de las fotografías de los genitales, éstos fueron primero ubicados en un portaobjeto con glicerina líquida para mejorar su visualización. Las fotografías finales se obtuvieron mediante la técnica fotográfica focus stacking con el software Zerene Stacker versión 1.04, y se editaron con el software Adobe Photoshop CS5 para mejorar aspectos visuales y unirlas. Las medidas se presentan en milímetros y fueron tomadas con un pie de metro digital Mitutoyo CD-6" ASX. El largo fue medido en la línea media entre la frente y el ápice del abdomen; el ancho fue medido entre los ángulos humerales; la proporción largo-ancho de los élitros fue calculada con el largo total y el ancho humeral; la proporción largo-ancho del pronoto fue calculada con el largo y ancho medio de éste. Los datos de cada etiqueta se transcriben textualmente entre comillas ( "'”), indicando la separación entre líneas con una barra diagonal ( / ), y doble barra diagonal ( / / ) señala cambio de etiqueta. Las siglas de las colecciones institucionales y privadas usadas en el texto son: Museo Nacional de Historia Natural, Santiago, Chile (MNNC); colección Alfredo Lüer H., Santiago, Chile (CALH); colección Wayne Seifert, Texas, Estados Unidos (CPWS); colección Cristian Pineda R., Valparaíso, Chile (CPCP); colección V. Manuel Diéguez, Santiago, Chile (CVMD).

\section{Resultados}

Eanus (Eanus) philippii (Fleutiaux, 1910)

(Figs. 1-8, 17, 18, 23, 24)

Localidad tipo. Osorno, Chile.

Diagnosis. Pronoto negro con los bordes laterales anaranjados; tegumento lustroso con punteado muy fino y disperso distribuido regularmente por toda la superficie. Élitros con tegumento negro lustroso; cada uno con ocho estrías finas bien definidas por hileras regulares de puntos; interestrías anchas con punteado muy fino y casi tan disperso como el del pronoto.

Redescripción. Macho ( $\mathrm{n}=1$ ). Largo: 10,94 mm; ancho: 2,74 mm. Cuerpo 3,99 veces más largo que ancho. Tegumento lustroso de color negro, excepto por los bordes laterales del pronoto anaranjados. Cabeza: Deprimida entre la frente y el vértice; irregularmente punteada con puntos gruesos setigeros concentrados en la depresión frontal y sobre los ojos, dejando una amplia área lisa sin puntos. Antenas con antenómeros 3-10 poco ensanchados apicalmente; antenómero 11 fusiforme. Palpos maxilares con último palpómero securiforme. Ojos fuertemente convexos. Tórax: Pronoto 1,25 veces más largo que ancho; regular y dispersamente punteado con puntos muy finos generalmente separados por 4-6 espacios de distancia entre sí. Margen anterior poco más ancho que la cabeza; sinuoso, formando dos pequeñas concavidades laterales y un lóbulo central ligeramente escotado en el medio. Márgenes laterales con una hilera de setas en el ángulo anterior que se atenúa hacia el centro; débilmente sinuados antes de los ángulos posteriores, estos fuertemente proyectados hacia los lados en forma de espinas. Prosterno e hipómeros con punteado setigero que se hace más grueso sobre la apófisis y el lóbulo prosternal. Apófisis prosternal ancha; lateralmente recta desde la base hasta el tercio distal en donde se estrecha abruptamente terminando en un ápice puntiagudo. Abdomen: Mesosterno con punteado setigero grueso y superficial; apófisis mesosernal con el margen posterior escotado medialmente. Ventritos I-IV subrectangulares; ventrito V el más largo, con el margen posterior convexo. Escutelo: Ovalado; finamente punteado. Élitros: 2,83 veces más largos que anchos; cada uno con ocho estrías finas definidas por hileras de puntos regularmente distribuidos; interestrías anchas con punteado tan fino y casi tan 
disperso como el del pronoto. Patas: Densamente cubiertas por hileras de setas rígidas; tarsos con tarsómeros filiformes, los cuales decrecen en longitud del 1 al 4; tarsómero 1 el más largo; tarsómero 4 el más corto; tarsómero 5 tan largo como el 3 y 4 combinados. Edeago: Parámeros con ápices en forma de lóbulos. Lóbulo medio de lados subparalelos, estrechándose en la parte distal de forma gradual hacia el ápice, que es agudo y redondeado en la punta. Placa basal casi igual de ancha que larga.

Hembra (n=1). Largo: 13,33 mm; ancho: 3,02 $\mathrm{mm}$. Cuerpo 4,41 veces más largo que ancho. Tórax: Pronoto 1,26 veces más largo que ancho; margen anterior notoriamente más ancho que la cabeza. Élitros: 2,48 veces más largos que anchos. Ovipositor: 19 veces más largo que ancho; báculos paraproctales finos, ensanchándose gradualmente desde la parte basal del gonocoxito hacia la base en donde se ensanchan abruptamente formando un gran lóbulo.
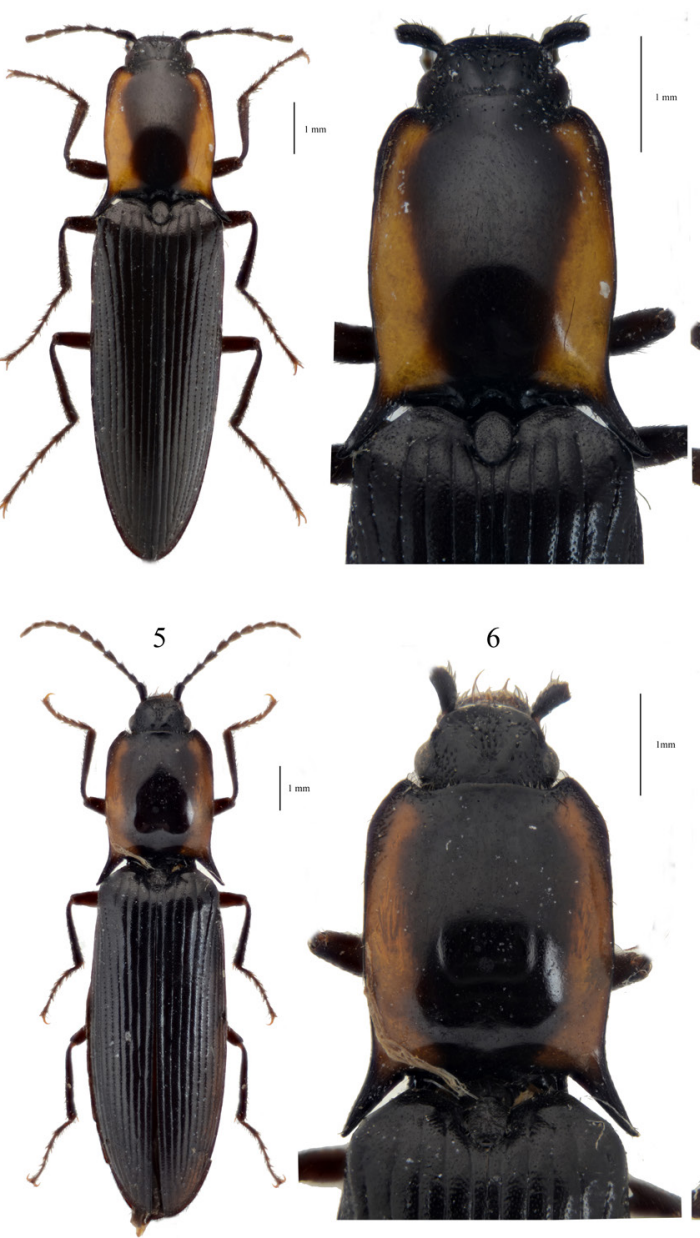

2

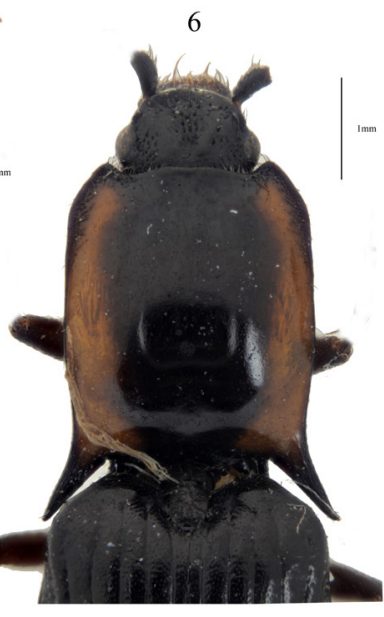

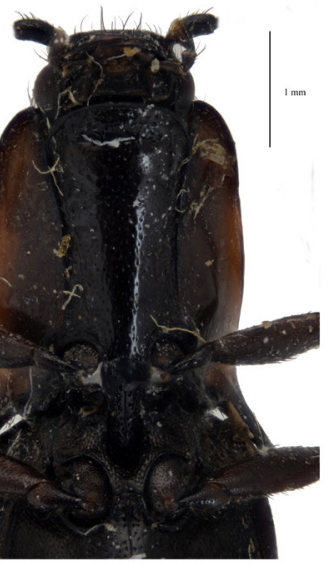

7

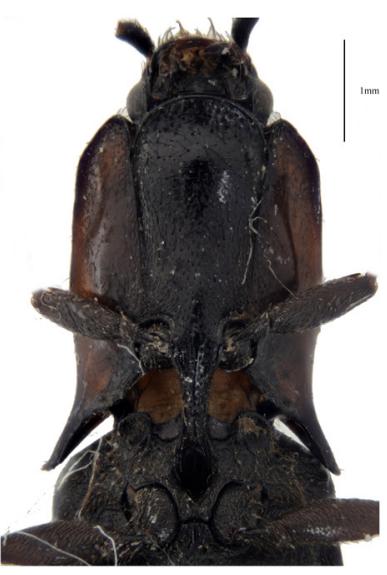

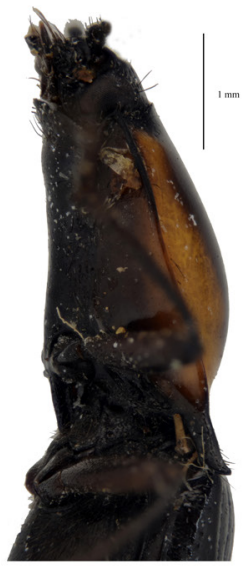

8

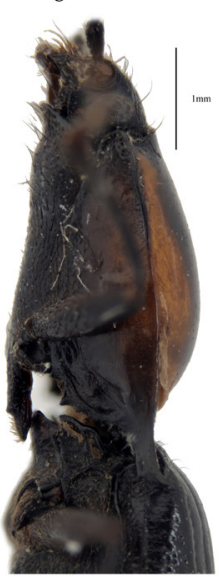

Figuras 1-8. Eanus (E.) philippii. Habito dorsal, detalle dorsal, ventral y lateral. 1-4. Macho. 5-8. Hembra.

Variación. Machos ( $\mathrm{n}=3$ ): Largo 10,94-10,99 mm. Hembras ( $\mathrm{n=4}$ ): Largo 12,97-13,33 mm. No se observaron variaciones de relevancia entre los ejemplares examinados.

Material examinado. Eanus philippii (Fleutiaux) (7 ejemplares). 1 hembra de: Chile, Región de Los Ríos, Provincia de Valdivia, Puerto Pirihueico, 14.I.1999, Alfredo Lüer leg. (CPAL); 1 
macho con los mismos datos que el anterior, excepto, 16.I.1999 (CPAL); 1 hembra de: Chile, Región de La Araucanía, Provincia de Malleco, Icalma, 13.I.2000, Alfredo Lüer leg. (CPAL); 1 macho con los mismos datos que el anterior, excepto, 18.XII.1995 (CPAL); 1 macho de: Chile, IX Región, Termas de Tolhuaca, 15/22.xii.1994, leg. Jensen y Vásquez (CVMD); 2 hembras de: T. Río Blanco, Chile, 7-18.01.92.

Distribución (Fig. 25). Chile, provincias de Malleco (Región de La Araucanía), Valdivia (Región de Los Ríos) y Osorno (Región de Los Lagos). Argentina, Provincia de Neuquén (Arias-Bohart y Elgueta 2012). Nuevo registro: Provincia de Cautín (Región de La Araucanía).

\section{Eanus (Eanus) densipunctatus nov. sp.}

(Figs. 9-16, 19-22)

Localidad tipo. Los Lleuques, Provincia de Diguillín, Región de Nuble, Chile.

Diagnosis. Tórax anaranjado, excepto por el prosterno y el margen anterior y posterior del pronoto negros; tegumento lustroso con punteado muy fino y disperso distribuido regularmente por toda la superficie, a excepción del área ocupada por la franja anterior de color negro que presenta un punteado más denso con puntos más gruesos y profundos que los del disco.

Holotipo macho. Largo: 12,48 mm; ancho: 3,08 mm. Cuerpo 4,0 veces más largo que ancho. Tegumento lustroso de color negro, exceptuando el disco del pronoto e hipómeros de color anaranjado. Cabeza: Deprimida entre la frente y el vértice; punteado setigero grueso e irregular concentrado densamente sobre la depresión frontal y sobre los ojos dando un aspecto corroído. Antenas con antenómeros 3-10 ensanchados apicalmente; antenómero 11 fusiforme. Palpos maxilares con el último palpómero securiforme. Ojos fuertemente convexos. Tórax: Pronoto 1,25 veces más largo que ancho; regular y dispersamente punteado con puntos muy finos generalmente separados por 4-6 espacios de distancia entre sí, exceptuando el área ocupada por la franja anterior de color negro que presenta un punteado más denso con puntos más gruesos y profundos que los del disco. Margen anterior un poco más ancho que la cabeza; sinuoso, formando dos pequeñas concavidades laterales y un lóbulo central ligeramente escotado en el medio. Márgenes laterales con una hilera de setas en el ángulo anterior que se atenúa hacia el centro; débilmente sinuados antes de los ángulos posteriores, estos fuertemente proyectados hacia los lados en forma de espinas. Prosterno e hipómeros con punteado setigero que se hace más grueso sobre la apófisis y el lóbulo prosternal. Apófisis prosternal ancha; levemente doblada lateralmente hacia la parte dorsal después de las procoxas, en donde se vuelve recta hasta el tercio distal, en el cual se estrecha abruptamente terminando en un ápice puntiagudo. Abdomen: Mesosterno densa y superficialmente punteado; apófisis mesosernal con margen posterior escotado medialmente. Ventritos I-IV subrectangulares; ventrito V el más largo, con margen posterior convexo. Escutelo: Ovalado; finamente punteado; moderadamente piloso. Élitros: 2,64 veces más largos que anchos; cada uno con ocho finas estrías claramente definidas por hileras de puntos regularmente distribuidos; interestrías anchas cubiertas de puntos tan finos y casi tan dispersos como los del pronoto. Patas: Densamente cubiertas por hileras de setas rígidas; tarsos con tarsómeros filiformes que decrecen en longitud del 1 al 4; tarsómero 1 el más largo; tarsómero 4 el más corto; tarsómero 5 tan largo como 3 y 4 combinados. Edeago: Parámeros con ápices en forma de lóbulos. Lóbulo medio estrechándose en curva hacia la parte distal en donde forma un lóbulo grueso con ápice redondeado. Placa basal casi 
igual de ancha que larga.

Hembra. Largo: 14,64 mm; ancho: 3,5 mm. Cuerpo 3,9 veces más largo que ancho. Tórax: Pronoto 1,06 veces más largo que ancho; margen anterior notoriamente más ancho que la cabeza. Élitros: 2,5 veces más largos que anchos. Ovipositor: 19 veces más largo que ancho; báculos paraproctales finos, ensanchándose muy gradualmente desde la parte basal del gonocoxito hacia la base en donde se ensanchan abruptamente formando un gran lóbulo.

9

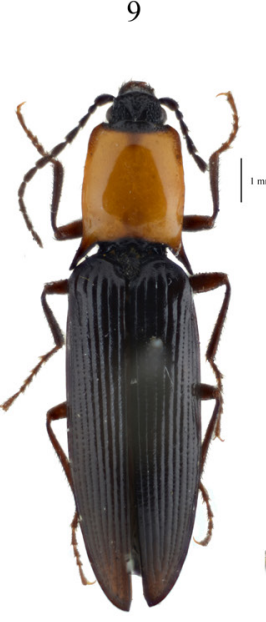

13

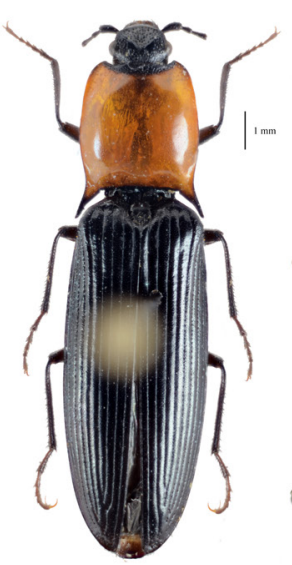

10

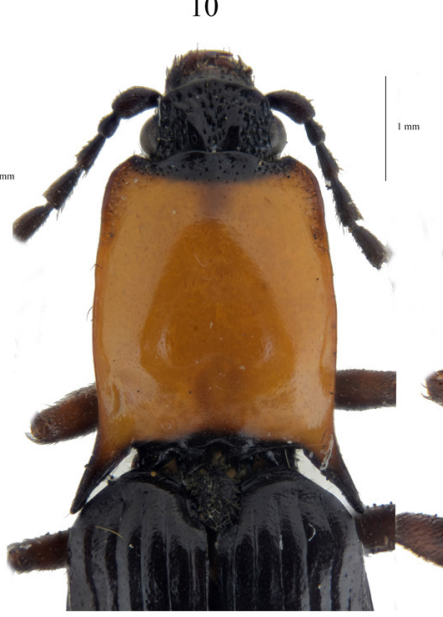

14
11
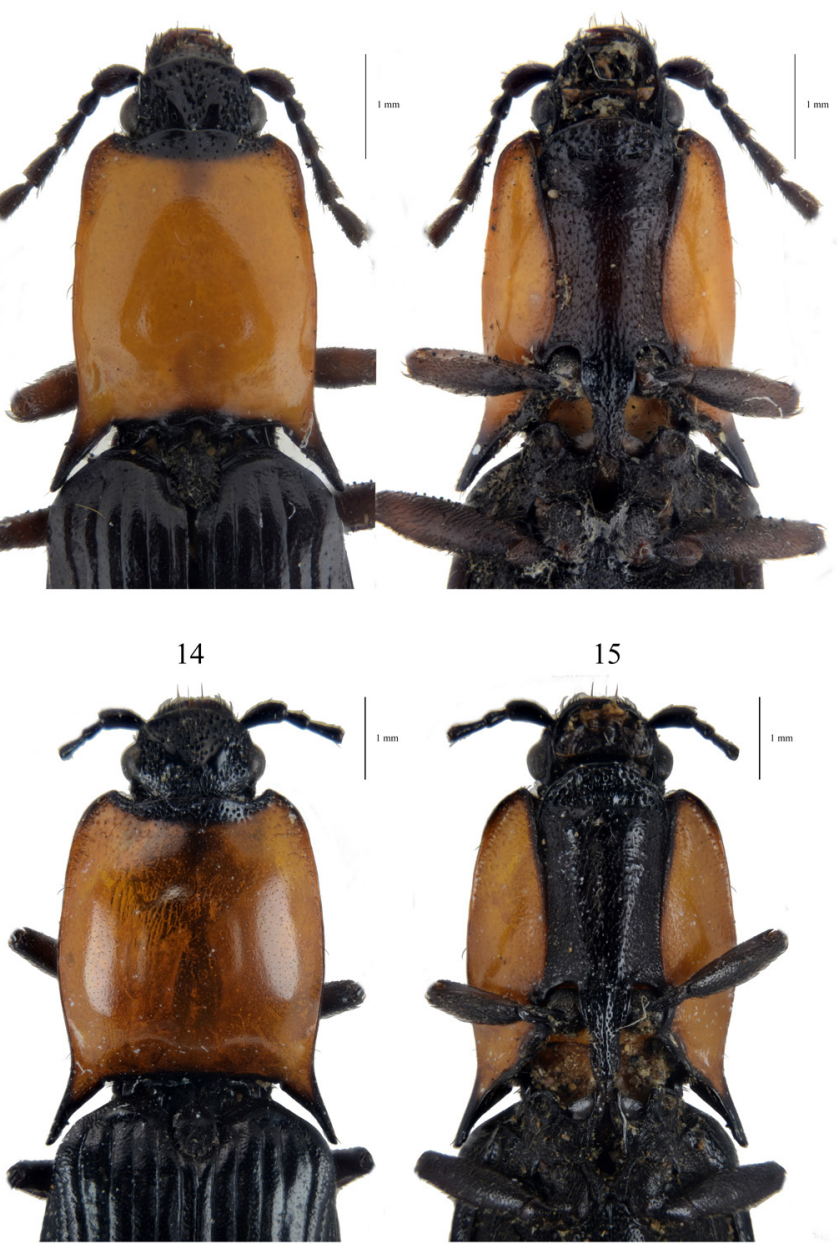

15

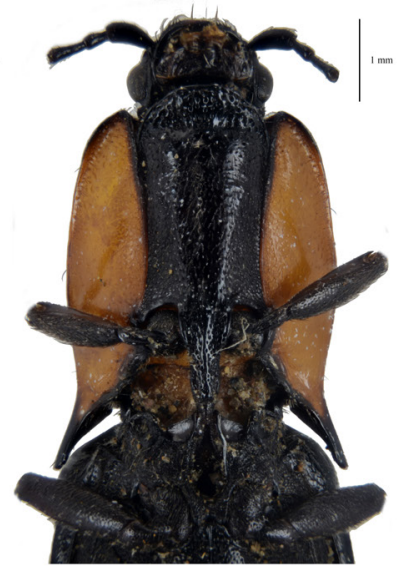

12

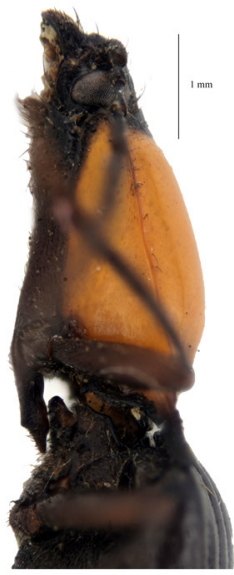

16

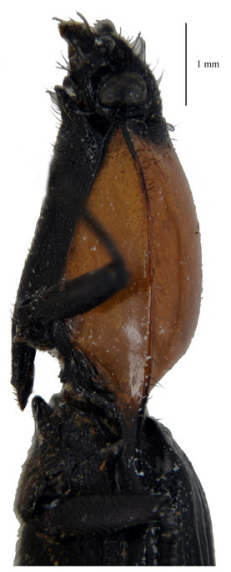

Figuras 9-16. E. (E.) densipunctatus nov. sp. Habito dorsal, detalle dorsal, ventral y lateral. 9-12. Macho. 13-16. Hembra.

Comparación. Eanus (E.) densipunctatus nov. sp., se diferencia de E. (E.) philippii por los caracteres que se enumeran a continuación (los caracteres de E. philippii se indican entre paréntesis): Cabeza con punteado setigero denso e irregular de aspecto corroído que cubre casi toda la superficie (irregularmente punteada con puntos setigeros gruesos concentrados en la depresión frontal y sobre los ojos, dejando amplias áreas lisas sin puntos). Pronoto anaranjado con borde anterior y posterior negro (negro con bordes laterales anaranjados); disco con punteado fino y disperso distribuido regularmente en la superficie salvo en el área ocupada por la franja anterior negra que posee un punteado más denso con puntos más gruesos y profundos que los del disco (disco con punteado 
fino y disperso distribuido regularmente en toda la superficie sin excepción del margen anterior).

Etimología. El nombre específico deriva del latín "densus" (denso) + "punctatus" (punteado), en referencia al punteado más denso y grueso presente en la cabeza y en la franja negra del margen anterior del pronoto que caracteriza al nuevo taxón.

Material tipo. Holotipo macho, etiquetado: “Los Lleuques / Nuble VIII / región CHILE / 28-11-88" / / "colección / V.M. Diéguez M." / / "Holotipo macho / Eanus (E.) densipunctatus nov. sp. / Pineda 2020" (MNNC). Paratipos: 1 hembra, etiquetada: “Chile, Región de Nuble, Provincia de Diguillín, Las Trancas, 18.XII.2014, Cristian Pineda leg." / / "Paratipo hembra / Eanus (E.) densipunctatus nov. sp. / Pineda 2020" (CPCP); 1 paratipo hembra, con los mismos datos que el anterior (CPWS).

17
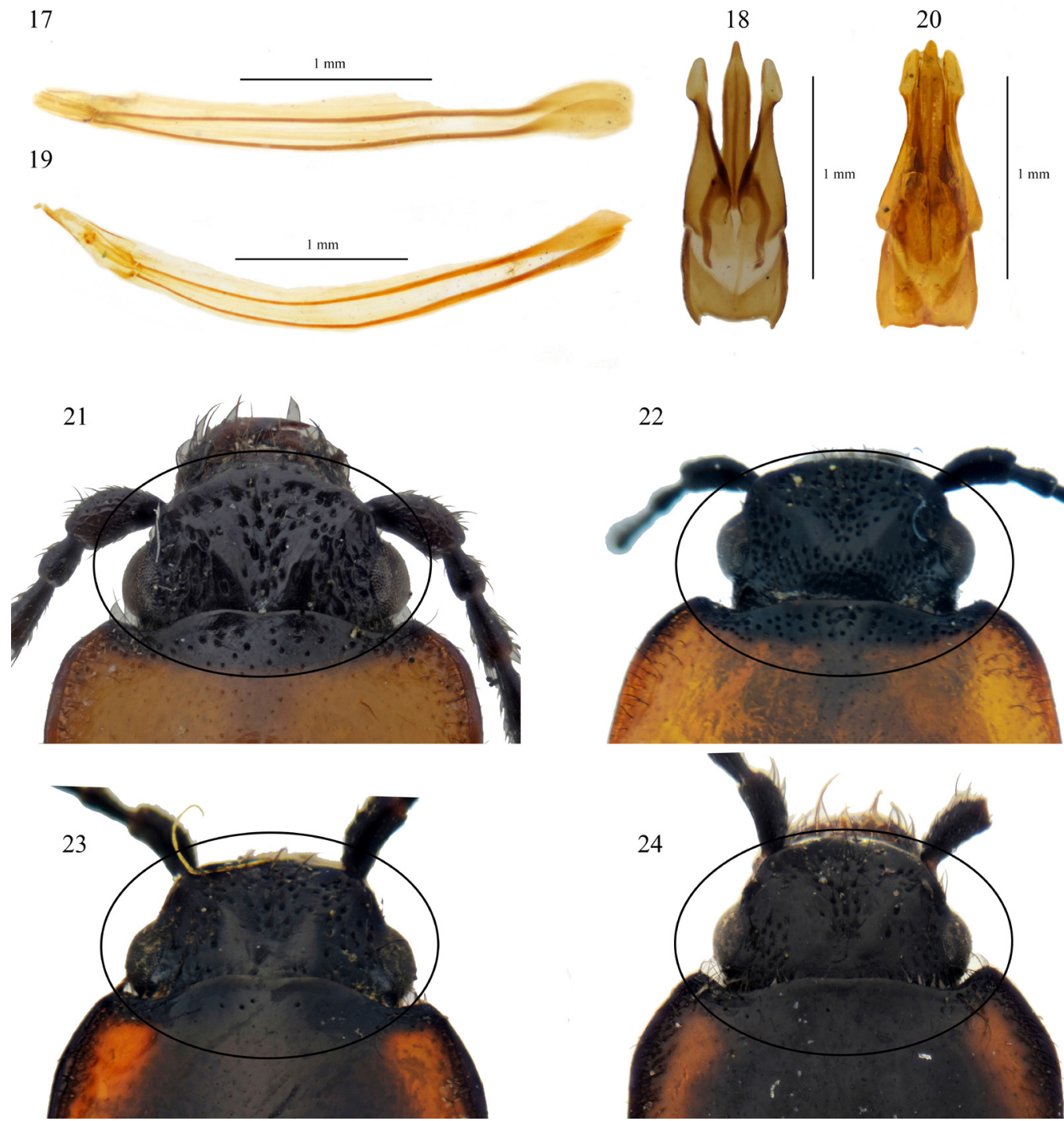

22

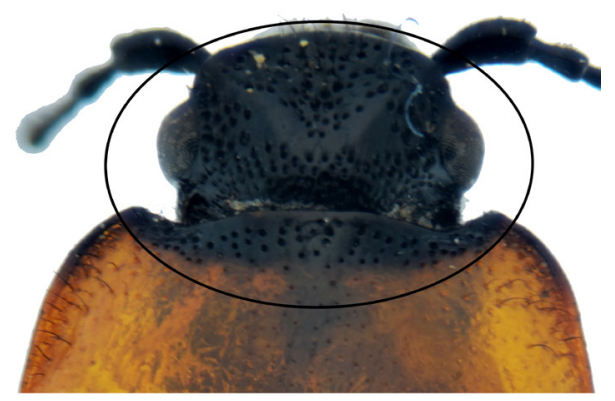

19
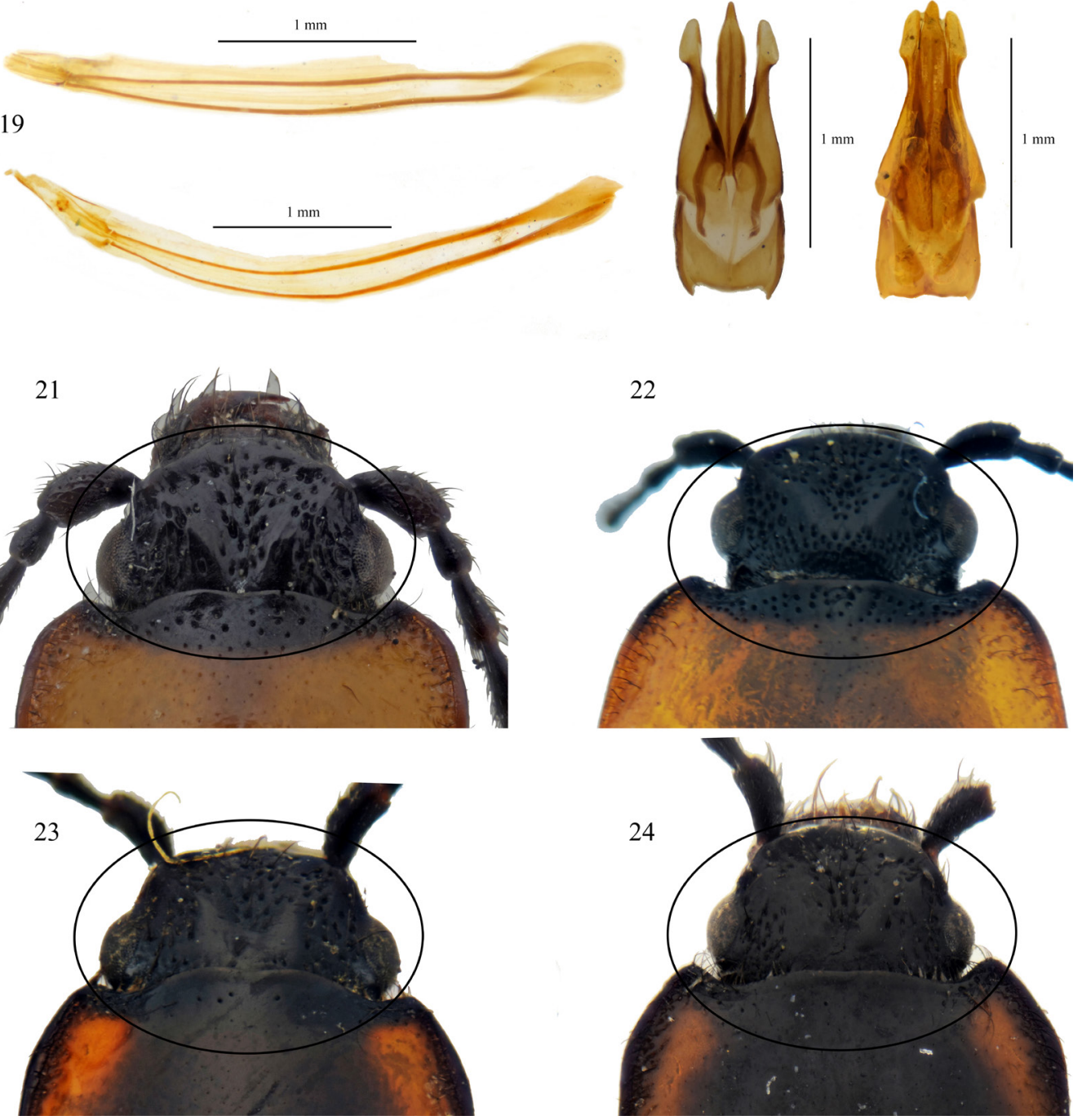

Figuras 17-24. Eanus (E.) spp. 17-18. E. philippii. 17. Ovipositor. 18. Edeago. 19-20. E. densipunctatus nov. sp. 19. Ovipositor. 20. Edeago. 21-24. Detalle de la cabeza y margen anterior del pronoto. 21-22. E. densipunctatus nov. sp. 23-24. E. philippii. 


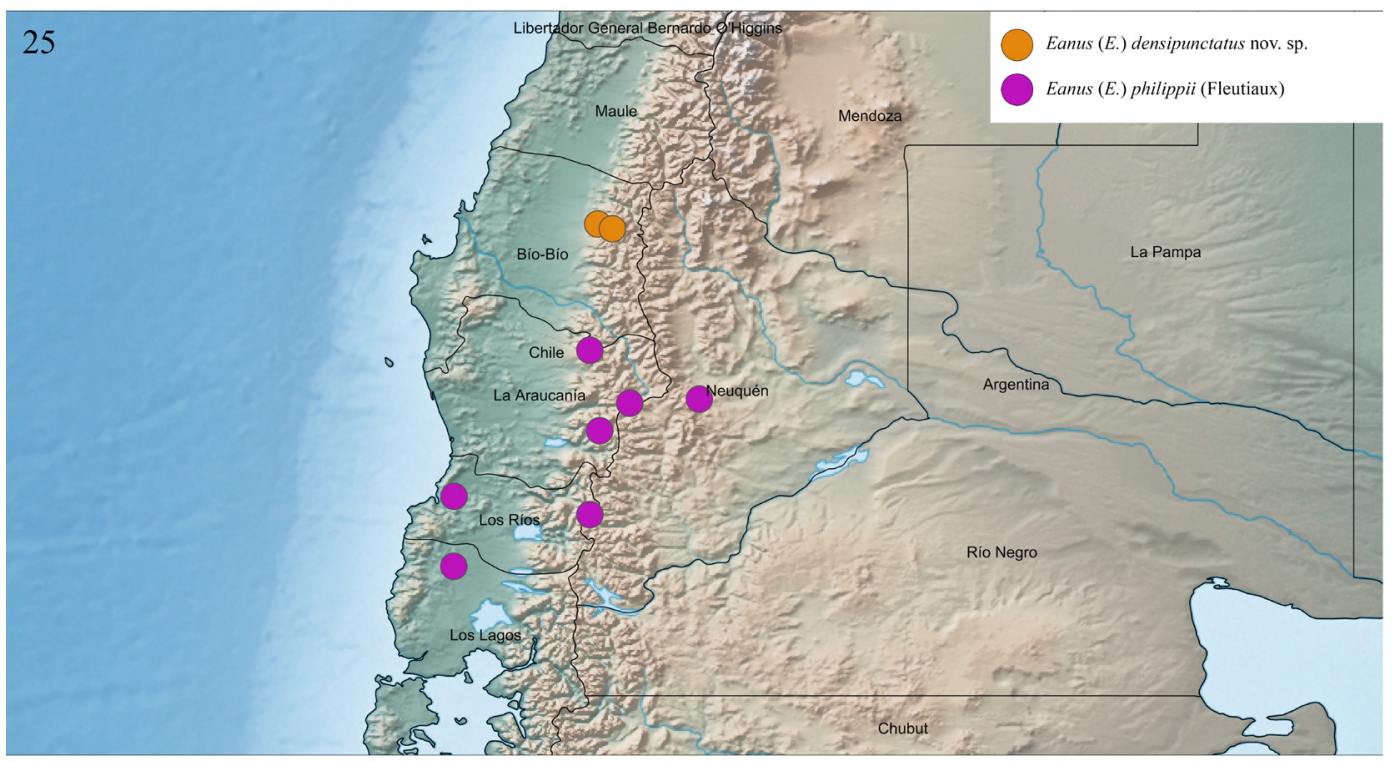

Figura 25. Distribución de E. (E.) philippii (Fleutiaux) y E. (E.) densipunctatus nov. sp. en Chile y Argentina.

\section{Agradecimientos}

A Alfredo Lüer, Wayne Seifert y Manuel Diéguez quienes colaboraron con parte del material examinado, y a Dariusz Tarnawski por proporcionar bibliografía importante de la familia Elateridae.

\section{Literatura Citada}

Arias-Bohart, E. y Elgueta, M. (2012) Catalogue of Chilean Elateridae. Annales Zoologic (Warszawa), 62(4): 643-668.

Fleutiaux, E. (1910) Elateridae et Melasidae nouveaux (Col.). Bulletin de la Société Entomologique de France, 1910: 174-176.

Lane, M.C. (1948) Some generic corrections in the Elateridae,I and II. (Coleoptera). Proceedings of the Entomological Society of Washington, 50(7): 179-182, 221-223.

Tarnawski, D. (2001) A World Catalogue of Ctenicerini Fleutiaux, 1936. Part II (Coleoptera: Elateridae: Athoinae). Genus, 12(3): 277-323. 